\title{
Mısır Tarımında Enerji Bilançosunun Belirlenmesi (Zea Mays L.)
}

\author{
Yusuf Dilay $^{1 *}$ \\ 1* Karamanoğlu Mehmetbey Üniversitesi, Teknik Bilimler Meslek Yüksekokulu, Makine ve Metal Teknolojileri Bölümü, Karaman, Türkiye, (ORCID: 0000-0002- \\ 5365-5137), ydilay@kmu.edu.tr
}

(İlk Geliş Tarihi 03 Ağustos 2021 ve Kabul Tarihi 24 Eylül 2021)

(DOI: 10.31590/ejosat.978458)

ATIF/REFERENCE: Dilay, Y. (2021). Mısır Tarımında Enerji Bilançosunun Belirlenmesi (Zea Mays L.). Avrupa Bilim ve Teknoloji Dergisi, (27), 583-587.

\section{$\ddot{O} z$}

Bu çalışmada, Türkiye'nin Karaman ili merkeze bağlı Taşkale köyünde mısır tarımında enerji bilançosunun belirlenmesi amaçlanmıştır. Denemeler Taşkale'de bulunan bir mısır üreticisinin işletmesinde gerçekleştirilmiştir. Denemelerde, enerji girdileri; insan işgücü enerjisi, makine enerjisi, dizel yakıt enerjisi, kimyasal gübre enerjisi, tohumluğun enerjisi ve sulama suyunun enerjileri olarak sınıflandırılmıştır. Üretim süresince bunların her birinin tüketimleri ayrı ayrı tespit edilerek girdi enerjileri hesaplanmıştır. Çıktı enerjisi ise, hasat edilen mısırın miktarı tespit edilerek, çıktı enerjisi hesaplanmıştır. Çalışmanın sonucunda mısır üretiminde enerji girdi ve çıktı değerleri $18029.78 \mathrm{MJ} \mathrm{ha}^{-1}$ ve $218700 \mathrm{MJ} \mathrm{ha}^{-1}$ olarak hesaplanmıştır. Girdi enerjileri; insan iş gücü $235.20 \mathrm{MJ} \mathrm{ha}^{-1}$ (\%1.30), makine 1575.29 $\mathrm{MJ} \mathrm{ha}^{-1}(\% 8.74)$, kimyasal gübreler $10910 \mathrm{MJ} \mathrm{ha}^{-1}(\% 60.51)$, dizel yakıt 3348.19 $\mathrm{MJ}^{-1}{ }^{-1}(\% 18.57)$, tohumluk $291.60 \mathrm{MJ} \mathrm{ha}^{-1}$ (\%1.62) ve sulama suyu $1669.5 \mathrm{MJ} \mathrm{ha}^{-1}$ (\%9.26) olarak hesaplanmıştır. Mısır üretiminde enerji oranı, özgül enerji, enerji üretkenliği ve net enerji üretimi sırasıyla; $12.13,1.20 \mathrm{MJ} \mathrm{kg}^{-1}, 0,83 \mathrm{~kg} \mathrm{MJ}^{-1}$ ve $200670.23 \mathrm{MJ} \mathrm{ha}^{-1}$ olarak bulunmuştur. Mısır tarımında toplam enerji girdileri içerisinde yenilenemeyen enerji girdilerinin oranın \%87.82 olduğu belirlenmiştir.

Anahtar Kelimeler: Enerji bilançosu, Enerji verimliliği, Mısır, Taşkale, Karaman.

\section{Determination of Energy Balance in Maize Agriculture (Zea Mays L.)}

\begin{abstract}
In this study, it was aimed to determine the energy balance in maize agriculture in Taşkale village of Karaman province in Turkey. The trials were carried out in the enterprise of a maize producer located in Taşkale. In the study, energy inputs; it was is classified as human labor energy, machine energy, diesel fuel energy, chemical fertilizer energy, seed energy and irrigation water energies. During the production, the consumptions of each of them were determined separately and their input energies were calculated. Output energy was calculated by determining the amount of harvested maize. As a result of the study, energy input and output values in maize production were calculated as $18029.78 \mathrm{MJ} \mathrm{ha}^{-1}$ and $218700 \mathrm{MJ} \mathrm{ha}^{-1}$. Input energies; human labour $235.20 \mathrm{MJ}^{-1}$ (1.30\%), machinery 1575.29 $\mathrm{MJ} \mathrm{ha}^{-1}(8.74 \%)$, chemical fertilizers $10910 \mathrm{MJ} \mathrm{ha}^{-1}(60.51 \%)$, diesel fuel 3348.19 $\mathrm{MJ} \mathrm{ha}^{-1}(18.57 \%)$, seeds $291.60 \mathrm{MJ}^{-1}(1.62 \%)$ and irrigation water were calculated as $1669.5 \mathrm{MJ} \mathrm{ha}^{-1}(9.26 \%)$. In maize production, energy ratio, specific energy, energy productivity and net energy production were respectively; it was found as $12.13,1.20 \mathrm{MJ} \mathrm{kg}^{-1}, 0.83 \mathrm{~kg} \mathrm{MJ}^{-1}$ and $200670.23 \mathrm{MJ}^{-1}$. It was been determined that the rate of non-renewable energy inputs among the total energy inputs in maize agriculture is $87.82 \%$.
\end{abstract}

Keywords: Energy balance, Energy productivity, Maize, Taşkale, Karaman.

\footnotetext{
* Sorumlu Yazar: ydilay@kmu.edu.tr
} 


\section{Giriş}

Dünya genelinde ekim alanı açısından 3. sırada yer alan mısır, üretim miktarı bakımından ise ilk sıradadır. Türkiye'de 638.829 hektarlık alanda tarımı yapılarak, yıllık yaklaşık 6.000.000 ton üretim hasat edilmektedir (TÜİK, 2021). Birim alandan alınan ürün miktarının yüksek olması, diğer ürünlere kıyasla tarımsal mekanizasyon araçlarının daha yoğun kullanılabilmesi gibi nedenlerle ülke genelinde tarımı günden güne artmaktadır. Dünyada üretilen mısırın büyük bir kısmı, gıda sektöründe ve hayvancılıkta kullanılırken, geri kalan kısmı ise, sanayide farklı sektörlerde kullanılmaktadır. Birim alandan yüksek tane verimi alınabilmesi ve çok fazla insan iş gücüne ihtiyaç duymaması nedeniyle günümüzde tarımsal üretimde önemli bir paya sahip olan misır türleri, yedi grupta incelenebilmektedir. Bunlar; at dişi mısır, sert mısır, şeker mısır, cin misırı, kavuzlu misır, unlu misır ve mumlu misırdır (Sönmez ve ark., 2013). Karaman'ında yer aldığı İç Anadolu Bölgesinde ise, genellikle silajlık ve dane misır tarımı yapılmaktadır.

Tarım ile enerji birbirinden ayrlamayacak iki önemli kavramdır. Tarımsal ürünler hem enerji alan hem de enerji verendir (Baran ve Gökdoğan, 2020). Bu nedenle tarımda enerji kullanımı verimlilik ve sürdürülebilirlik açısından son derece büyük öneme sahiptir. Artan dünya nüfusunun gıda talebine karşın tarım alanlarının gittikçe azalması birim alandan daha fazla ürün almayı gerektirir. Bu durum tarımda yoğun bir enerji kullanımını kaçınılmaz kılmaktadır. Tarımsal üretimde minimum enerji girdileri ile maksimum verimin elde edilmesi her dönemde arzu edilen bir durumdur (Alam ve ark., 2005). Tarımda verimli enerji kullanımı ile maddi anlamda tasarruf yapılırken, aynı zamanda fosil yakıt tüketiminin ve hava kirliliğinin azaltılması da sağlanacaktır. Böylelikle sürdürülebilir tarımsal üretim yapılmış olacaktır (Uhlin, 1998; Azarpour ve ark., 2013).

Çeşitli tarımsal ürünlerin enerji bilançoları farklı araştırmacılar tarafından hesaplanmıştır. Mısır (Konak ve ark., 2004; Azarpour ve ark., 2013; Karaağaç ve ark., 2014), soya fasulyesi (Mandal ve ark., 2002), hardal (Mandal ve ark., 2002), buğday-mısır (Mani ve ark., 2007), çerezlik kabak (Baran ve Gökdoğan, 2020; Sağlam ve Çetin, 2018), patates (Mohammadi ve ark., 2008), salatalık (Mohammadi ve Omid, 2010), kanola (Mousavi-Avval ve ark., 2011), mercimek (Mirzae ve ark., 2011), mısır (Karaağaç ve ark., 2011), susam (İbrahim, 2011), arpa (Azizi ve Heidari, 2013), tütün (Loghmanpour-zarini ve Abedifirouzjaee, 2013), pirinç (Yadav ve ark., 2013; Baran ve ark., 2015), üzüm (Baran ve ark., 2017), narenciye (Yılmaz ve Aydın, 2020), domates (Saltuk, 2019a), nohut (Marakoğlu ve ark., 2010; Karaağaç ve ark., 2019), yerfıstığı (Baran ve ark., 2018, Saltuk, 2019b) ve limonun (Bilgili, 2012) enerji bilançosunu hesaplamışlardır. Bu çalışmada ise, Karaman ili Taşkale köyünde mısır tarımında enerji bilançosunun hesaplanması amaçlanmıştır.

\section{Materyal ve Metot}

Karaman $37.033^{\circ}$ Kuzey enlemleri ve $33.2785^{\circ}$ Doğu boylamları arasında coğrafi olarak yer almaktadır (Şekil 1). İlinin yüzölçümü $3686 \mathrm{~km}^{2}$ dir (Anonim, 2021). Çalışma, Karaman il merkezine yaklaşık $45 \mathrm{~km}$ uzaklıktaki Taşkale köyünde bulunan 20 dekarlık sulanabilen bir tarlada, 2500'er metrekarelik test alanlarında 2020 yılında gerçekleştirilmiştir.

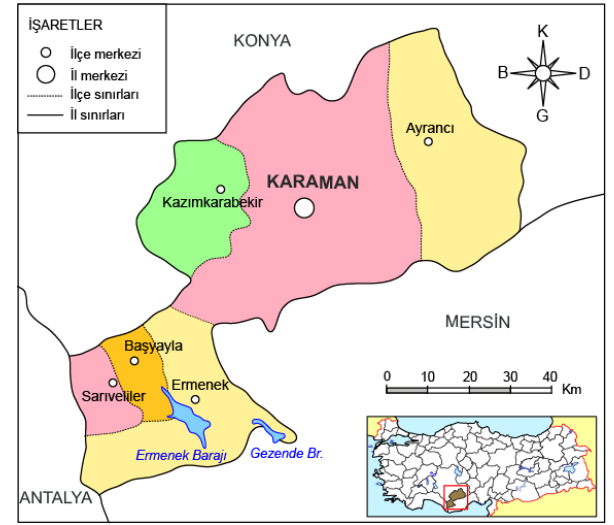

Şekil 1. Denemelerin yapıldığı alanın coğrafi konumu (Anonim, 2021)

$\mathrm{Bu}$ çalışmada üç tekerrürlü tesadüfi blok deseni kullanılmıştır. Girdi ve çıktı enerjileri bulunurken, her bir bileşenin enerji eşdeğerleri katsayılarının, bir dönem mısır üretiminde kullanılan miktarları ile çarpılarak hesaplanmıştır. Hesaplamalarda kullanılan enerji eşdeğer katsayıları yapılan önceki araştırmalardan alınmıştır. Mısırın girdi ve çıktı değerleri hesaplanarak, Tablo 2'de verilmiştir. Koçtürk ve Engindeniz (2009), Singh ve ark. (2003) ve Mandal ve ark. (2002), girdi enerjilerini doğrudan-dolaylı ve yenilenebilir-yenilenemeyen enerjiler olarak sınıflandırmışlardır. Yapılan çalışmada mısır tarımında enerji hesaplamaları Tablo 3 'te, girdi enerji türleri ise Tablo 4'te verilmiştir.

Her parselin toplam yakıt tüketimi 1 ha-1 olarak hesaplanmıştır. Yakıt tüketimini ölçmek için tam dolu depo yöntemi kullanılmıştır (Göktürk, 1999; El Saleh, 2000; Sonmete, 2006). Her parselin $\left(\right.$ ha $\left.h^{-1}\right)$ iş gücü verimi, deneme alanında hesaplanan toplam sürenin alana bölünmesiyle hesaplanmıştır. Parseldeki deneylerde etkin çalışma süresi (tef) kullanılarak ölçülmüştür (Özcan, 1986; Güzel, 1986; Sonmete, 2006). Üretimin her aşamasında çalışma süreleri kronometre yardımıyla ölçülmüştür. Mısır tarımında kullanılan girdi-çıktı enerji değerleri Tablo 1'de verilmiştir. Enerji oranı, özgül enerji, enerji üretkenliği ve net enerji ise, aşağıda verilen formüller yardımıyla hesaplanmıştır (Mandal ve ark., 2002; Mohammadi ve ark., 2010; Baran ve Gökdoğan, 2020).

Enerji oranı $=$ Enerji çıktısı $\left(\mathrm{MJ} \mathrm{ha}^{-1}\right) /$ Enerji girdisi $\left(\mathrm{MJ} \mathrm{ha}^{-1}\right)(1)$ Özgül enerji $\left(\mathrm{MJ} \mathrm{kg}^{-1}\right)=$ Toplam enerji girdisi $\left(\mathrm{MJ} \mathrm{ha}^{-1}\right) /$ Hasat edilen toplam ürün miktarı $\left(\mathrm{kg} \mathrm{ha}^{-1}\right)$

Enerji üretkenliği $\left(\mathrm{kg} \mathrm{Mj}^{-1}\right)=$ Hasat edilen toplam ürün miktarı $\left(\mathrm{kg} \mathrm{ha}^{-1}\right) /$ Toplam enerji girdisi $\left(\mathrm{MJ} \mathrm{ha}^{-1}\right)$

Net enerji $\left(\mathrm{MJ} \mathrm{ha}^{-1}\right)=$ Enerji çıktısı $\left(\mathrm{MJ} \mathrm{ha}^{-1}\right)$ - Enerji girdisi $(\mathrm{MJ}$ $\mathrm{ha}^{-1}$ ) 
Tablo 1. Mısır üretiminde girdi ve çıktıların enerji eşdeğerleri

\begin{tabular}{lccl}
\hline Giriş & Birim & $\begin{array}{c}\text { Enerji eşdeğeri } \\
\left(\mathbf{M J} \text { ünitesi }^{-1}\right)\end{array}$ & Kaynaklar \\
\hline İnsan iş gücü & $\mathrm{h}$ & 1.96 & Mani ve ark., 2007; Karaağaç ve ark., 2011 \\
\hline Makine & $\mathrm{h}$ & 64.80 & Singh, 2002; K1zllaslan, 2009 \\
\hline Kimyasal gübreler & & & \\
\hline Üre & $\mathrm{kg}$ & 36.61 & Tozan ve ark., 2001 \\
\hline DAP & $\mathrm{kg}$ & 11.96 & Tozan ve ark., 2001 \\
\hline Dizel yakıt & 1 & 56.31 & Singh, 2002; Demircan ve ark., 2006 \\
\hline Tohum & $\mathrm{kg}$ & 14.58 & Pimentel, 1980 \\
\hline Sulama suyu & $\mathrm{m}^{3}$ & 0.63 & Barut ve ark., 2011 \\
\hline Çıtı & & & \\
Verim (Dane Misır) & $\mathrm{kg}$ & 104 & Barut ve ark., 2011; Öztürk, 2011 \\
\hline
\end{tabular}

\section{Araştırma Sonuçları ve Tartışma}

Mısır tarımı yapılan işletmede 2020 yılında birim alandan ortalama $15000 \mathrm{~kg} \mathrm{ha}^{-1}$ mısır alınmıştır. Yapılan mısır üretimde hesaplanan enerji bilançosu değerleri Tablo 2'de verilmiştir. Tablo 2'ye göre, mısır üretimindeki enerji girdileri toplamı18029.78 MJ $\mathrm{ha}^{-1}$, enerji çıtısı toplamı ise, $218700 \mathrm{MJ} \mathrm{ha}^{-1}$ olarak hesaplanmıştır. Enerji girdileri; insan iş gücü $235.20 \mathrm{MJ} \mathrm{ha}^{-1}$ (\%1.30), makine enerjisi $1575.29 \mathrm{MJ} \mathrm{ha}^{-1}$ (\%8.74), kimyasal gübrelerin toplam enerjisi $10910 \mathrm{MJ} \mathrm{ha}^{-1}(\% 60.51)$, dizel yakıtın enerjisi 3348.19 $\mathrm{MJ}^{-1}$ (\%18.57), tohumun enerjisi $291.60 \mathrm{MJ}$ $\mathrm{ha}^{-1}(\% 1.62)$ ve sulama suyunun enerjisi $1669.5 \mathrm{MJ} \mathrm{ha}^{-1}(\% 9.26)$ olarak hesaplanmıştır. Enerji girdileri içerisinde kimyasal gübrelerin enerjisinin \%60.51 ile en yüksek paya sahip olduğu görülmüştür. Daha önce yapılan çalışmalarda da araştırmacılar, mısır yada farklı bazı ürünlerde kimyasal gübrelerin enerji girdilerini yüksek oranlarda bulmuşlardır. Mısır tarımında Baran ve ark. (2017) \%57.06, Baran ve Gökdoğan (2020) \%52.55 ile kimyasal enerji girdisinin, toplam enerji girdileri içerisindeki payının en yüksek değerde olduğunu bildirmişlerdir. Mohammadi ve Omid (2010) salatalık tarımında \%40.17, Abbas (2011), kanola tarımında \%36.30, Karaağaç ve ark. (2011) buğday tarımında
\%58.21 ile toplam enerji girdileri içerisinde kimyasal gübrelerin enerjilerinin en büyük paya sahip olduğunu bildirmektedirler.

Mısır üretiminde enerji oranı, özgül enerji, enerji üretkenliği ve net enerji üretimi sırasıyla $12.13,1.20 \mathrm{MJ} \mathrm{kg}^{-1}, 0.83 \mathrm{~kg} \mathrm{MJ}^{-1} \mathrm{ve}$ 200670.23 $\mathrm{MJ} \mathrm{ha}^{-1}$ olarak bulunmuştur (Tablo 3). Daha önceki yapılan araştırmalarda enerji üretkenliği; Sağlam ve Çetin (2018) 1.005 (kabak çekirdeği), Mandal ve ark. (2002) 1.10 (soya fasulyesi), 1.98 (hardal), Mohammadi ve ark. (2008) 1.25 (patates) olarak hesaplamışlardır.

Misır üretiminde tüketilen toplam girdi enerjilerinin; \%29.13'ü doğrudan, \%70.87'si dolaylı, \%12.18'i yenilenebilir ve \%87.82'si ise yenilenemeyen enerjiler olarak sınıflandırılmıştır (Tablo 4). Yapılan diğer çalışmalarda da; Azarpour ve ark. (2013) yenilenebilir enerji oranını \%5,68 (kabak çekirdeği), Mohammadi ve ark. (2008) \%25,73 (patates), Mohammadi ve Omid (2010) \%6,85 (salatalık), Abbas (2011) \%1,20 (kanola), Loghmanpourzarini ve Abedi-firouzjaee (2013)'de \%16,55 (tütün) olarak hesaplamışlardır. Görüleceği gibi Abbas (2011) haricinde diğer araştırmacılar yenilenebilir enerji oranını daha yüksek bulmuşlardır. Çalışmada yenilenemeyen enerji oranı ise \%97.08 ile oldukça yüksek bir oranda bulunmuştur.

Tablo 2.Mısır üretiminde enerji bilançosu

\begin{tabular}{|c|c|c|c|c|c|}
\hline Giriş & Birim (br) & $\begin{array}{c}\text { Enerji eşdeğeri (MJ } \\
\left.\text { br }^{-1}\right)\end{array}$ & $\begin{array}{c}\text { Hektara başına } \\
\text { düşen girdi (birim } \\
\text { ha }^{-1} \text { ) }\end{array}$ & $\begin{array}{l}\text { Enerji değeri (MJ } \\
\left.\qquad h^{-1}\right)\end{array}$ & $\begin{array}{c}\text { Oran } \\
(\%)\end{array}$ \\
\hline İnsan iş gücü & $\mathrm{h}$ & 1.96 & 120 & 235.20 & 1.30 \\
\hline Makine & $\mathrm{h}$ & 64.80 & 24,31 & 1575.29 & 8.74 \\
\hline Kimyasal gübreler & & & & 10910.00 & 60.51 \\
\hline -DAP & $\mathrm{kg}$ & 36.61 & 200 & 7322.00 & 40.61 \\
\hline -Üre & $\mathrm{kg}$ & 11.96 & 300 & 3588.00 & 19.90 \\
\hline Dizel yakıt & 1 & 56.31 & 59.46 & 3348.19 & 18.57 \\
\hline Tohum & $\mathrm{kg}$ & 14.58 & 20 & 291.60 & 1.62 \\
\hline Sulama suyu & $\mathrm{m}^{3}$ & 0.63 & 2650 & 1669.5 & 9.26 \\
\hline Toplam & & & & 18029.78 & 100.00 \\
\hline Çıktı & Birim (br) & $\begin{array}{l}\text { Enerji eşdeğeri } \\
\left(\mathrm{MJ} \mathrm{birim}^{-1}\right)\end{array}$ & Verim (birim ha ${ }^{-1}$ ) & Enerji değeri (MJ ha'-1) & $\begin{array}{c}\text { Oran } \\
(\%)\end{array}$ \\
\hline Verim (Dane Misir) & $\mathrm{kg}$ & 14.58 & 15000 & 218700 & 100.00 \\
\hline Toplam & & & & 218700 & 100.00 \\
\hline
\end{tabular}


Tablo 3.Misır üretiminde enerji hesaplamalart

\begin{tabular}{llr}
\hline Hesaplama & Birim & Değer \\
\hline Enerji oranı & & 12.13 \\
\hline Özgül enerji & $\mathrm{MJ} \mathrm{kg}^{-1}$ & 1.20 \\
\hline Enerji üretkenliği & $\mathrm{kg} \mathrm{MJ}^{-1}$ & 0.83 \\
\hline Net enerji üretimi & $\mathrm{MJ} \mathrm{ha}^{-1}$ & 200670.23 \\
\hline
\end{tabular}

Tablo 4. Misır için enerji girdisi türleri

\begin{tabular}{|c|c|c|}
\hline Enerji türü & $\begin{array}{c}\text { Enerji girişi } \\
\left(\mathbf{M J ~ h a}^{-1}\right)\end{array}$ & $\begin{array}{c}\text { Oran } \\
(\%)\end{array}$ \\
\hline Doğrudan enerji ${ }^{\text {a }}$ & 5252.89 & 29.13 \\
\hline Dolaylı enerji ${ }^{b}$ & 12776.89 & 70.87 \\
\hline Toplam & 18029.78 & 100.00 \\
\hline Yenilenebilir enerji $^{\mathrm{c}}$ & 2196.30 & 12.18 \\
\hline Yenilenemeyen enerji ${ }^{\mathrm{d}}$ & 15833.48 & 87.82 \\
\hline Toplam & 18029.78 & 100.00 \\
\hline
\end{tabular}

a İnsan emeği su ve dizel yakıt içerir

$\mathrm{b}$ Tohum, kimyasal gübreler ve makineler içerir

c İnsan emeği, su ve tohum içerir

$\mathrm{d}$ Dizel yakıt, kimyasal gübreler ve makineler içerir

\section{Sonuç}

Çalışma şu özetlenmiş sonuçlarla açıklanmıştır:

Mısır tarımında toplam enerji tüketimi $18029.78 \mathrm{MJ} \mathrm{ha}^{-1}$ olarak bulunmuştur. Bunun içerisinde en yüksek payı kimyasal gübrelemeler (\%60.51) alırken, bunu sirasıyla dizel yakıtın enerji girdisi (\%18.57) ve sulama suyunun enerji girdisi (\%9.26) izlemiştir.

Enerji oran1, özgül enerji, enerji üretkenliği ve net enerji üretimi değerleri ise sirasıyla 12.13, $1.20 \mathrm{MJ} \mathrm{kg}^{-1}, 0.83 \mathrm{~kg} \mathrm{MJ}^{-1}$ ve 200670.23 $\mathrm{MJ} \mathrm{ha}^{-1}$ olarak hesaplanmıştır.

Yenilenebilir ve yenilenemeyen enerji girdileri toplam enerji girdisinin oranları ise, $\% 12.18$ ve $\% 87.82$ olarak gerçekleşmiştir. Hesaplanan verilere bakılacak olursa enerji verimliliğinin artırılması için tarımsal üretimde kimyasalların kullanımının olabildiğince azaltılması, üretimde kimyasal gübreler yerine çiftlik gübresinin kullanımının teşvik edilmesi gerekir.

$\mathrm{Bu}$ çalışmada Karaman ilinde mısır üretiminin enerji verimliliği belirlenmiştir. Değerlendirme sonuçlarına göre, çalışma alanında mısır tarımının enerji oranı (çıktı/girdi) 12.13 olarak hesaplanmış olup, enerji kullanımı açısından ekonomik bir üretim olduğu söylenebilir.

\section{Kaynakça}

Abbas, D. (2011). Energy use efficiency and economic analysis of canola production in three different areas in Iran. Journal of Agricultural and Biological Science, 6(11), 54-61.

Alam, M. S., Alam, M. R., Islam, K. K. (2005). Energy flow in Agriculture: Bangladesh. American Journal of Environmental Sciences. 1(3), 213-220.

Anonim, 2021. Karaman Valiliği. http://www.karaman.gov.tr/ilincografi-bilgileri Erişim tarihi: 08.06.2021.

Azarpour, E., Mehr, A. S., Moraditochaee, M., Reza, H. (2013). Evaluation greenhouse gases and energy of pumpkin production in north of Iran. International Journal of Biosciences, 3(8), 182-190.
Azizi, A., Heidari, S. (2013). A comparative study on energy balance and economical indices in irrigated and dry land barley production systems. International Journal of Environment Science and Technology, 10(5), 1019-1028.

Baran, M. F., Gökdoğan, O., Bağdatl, C., Bellitürk, K. (2015). Energy balance of rice production in Turkey: A case study for Kirklareli province, Ecronicon Open Access Agriculture, 1(4), 167-173.

Baran, M. F., Lüle, F., Gökdoğan, O. (2017). Energy input-output analysis of organic grape production: A case study from Adiyaman province. Erwerbs-Obstbau, 59, 275-279.

Baran M.F, Karaağaç, H. A, Bolat, A, Çil A., Çil, A.N. (2018). Yerfistığ 1 üretiminde enerji kullanım etkinliğinin belirlenmesi (Adana ili örneği). Avrupa Bilim ve Teknoloji Dergisi, (15), 103-111.

Baran, M. F., \& Gökdoğan, O. (2020). Determination of Energy Balance in Pumpkin Seed (Cucurbita pepo L.) Production. Avrupa Bilim ve Teknoloji Dergisi, (19), 43-47.

Barut, Z.B., Ertekin, C., Karaağaç, H.A. (2011). Tillage Effects on Energy Use for Corn Silage in Mediterranean Coastal of Turkey. Enegy, 36, 9, 5466-5475.

Bilgili, M. E. (2012). Limon üretiminde enerji kullanım etkinliğinin belirlenmesi; Adana İli Örneği. Tarım Makinaları Bilimi Dergisi. Cilt 8, Sayı 2. s199-203.

Demircan, V., Ekinci, K., Keener, H.M., Akbolat, D., Ekinci, Ç. (2006). Energy and economic analysis of sweet cherry production in Turkey: A case study from Isparta province. Energy Conversion and Management, 47, 1761-1769.

El Saleh, Y. (2000). Suriye ve Türkiye'de mercimek ve nohut hasadında mekanizasyon olanaklarının belirlenmesi üzerine bir araştırma. Doktora Tezi, Çukurova Üniversitesi Fen Bilimleri Enstitüsü (Yayımlanmamış), Adana.

Göktürk, B. (1999). Kuru soğanın hasada yönelik bazı özelliklerinin saptanması, kazıcı bıçaklı tip hasat makinesinin geliştirilmesi ve diğer hasat yöntemleri ile karşılaştırılması üzerine bir araştırma. Doktora Tezi, Trakya Üniversitesi Fen Bilimleri Enstitüsü (Yayımlanmamış), Tekirdağ.

Güzel, E. (1986). Çukurova Bölgesinde yerfıstığının söküm ve harmanlanmasının mekanizasyonu ve bitkinin mekanizasyona yönelik özelliklerinin saptanması üzerine bir 
araştırma. Türkiye Zirai Donatım Kurumu Mesleki Yayınları, Yayın No: 47, Ankara.

İbrahim, H.Y. (2011). Kuzey Orta Nijerya'da susam üretimi için enerji girdileri ve mahsul verimi ilişkisi. Tarım Teknolojisi Dergisi, 7(4), 907-914.

Karaağaç, M. A., Aykanat, S., Çakır, B., Eren, Ö., Turgut, M.M., Barut, Z.B., Öztürk, H. H. (2011). Energy balance of wheat and maize crops production in Haciali Undertaking. 11th International Congress on Mechanization and Energy in Agriculture Congress, 388-391.

Karaağaç, H. A., Aykanat, S., Gültekin, R., \& Baran, M. F. (2014). Adana'da Ana Ürün Mısır Üretiminde Enerji Kullanım Etkinliğinin Belirlenmesi. Namık Kemal Üniversitesi Tekirdă̆ Ziraat Fakültesi Dergisi 11 (3), 75-81.

Karaağaç, H. A, Baran M. F, Mart, D., Bolat, A., Eren, Ö. (2019). Nohut üretiminde enerji kullanım etkinliği ve sera gazı (GHG) emisyonunun belirlenmesi (Adana ili örneği). Avrupa Bilim ve Teknoloji Dergisi, (16), 41-50.

Kizilaslan, H. (2009). Input-output energy analysis of cherries production in Tokat Province of Turkey. Appled Energy. 86, 1354- 1358.

Koçtürk, O.M., Engindeniz, S. (2009). Energy and cost analysis of sultana grape growing: a case study of Manisa, west Turkey. African Journal of Agricultural Research, 4(10), 938943.

Konak, M., Marakoğlu, T., \& Özbek, O. (2004). Mısır Üretiminde Enerji Bilançosu. Selcuk Journal of Agriculture and Food Sciences, 18(34), 28-30.

Kosemani, B. S., \& Bamgboye, I. A. (2021). Modelling energy use pattern for maize (Zea mays L.) production in Nigeria. Cleaner Engineering and Technology, 100051.

Loghmanpour-zarini, R., Abedi-firouzjaee, R. (2013). Energy and water use indexes for Tobacco production under different irrigation systems in Iran. International Journal of Agriculture and Crop Sciences, pp: 5-12/1332-1339.

Mandal, K.G., Saha, K.P., Ghosh, P.K., Hati, K.M., Bandyopadhyay, K.K. (2002). Orta Hindistan'da soya bazlı mahsul üretim sistemlerinin biyoenerjisi ve ekonomik analizi. Biyokütle ve Biyoenerji, 23, 337-345.

Mani, I., Kumar, P., Panwar J.S., Kant, K. (2007). Variation in energy consumption in production of wheat-maize with varying altitudes in Hill Regions of Himachal Prades, India. Energy, 32, 2336-2339.

Marakoğlu, T., Özbek, O., \& Çarman, K. (2010). Nohut üretiminde farklı toprak işleme sistemlerinin enerji bilançosu. Tarım Makinaları Bilimi Dergisi, 6(4), 229-235.

Mirzaee, E., Omid, M., Asakereh, A., Safaieenejad, M. and Dalvand M. J. (2011). Uluslararası Tarımda Mekanizasyon ve Enerji Kongresi, 21-23 Eylül, İstanbul, Türkiye, 383-387.

Mohammadi, A., Tabatabaeefar, A., Shahin, S., Rafiee, S., Keyhani, A. (2008). Energy use and economical analysis of potato production in Iran a case study: Ardabil Province. Energy Conversion Management, 49, 3566-3570.

Mohammadi, A., Omid, M. (2010). Economical analysis and relation between energy inputs and yield of greenhouse cucumber production in Iran. Applied Energy, 87, 191-196.

Mohammadi, A., Rafiee, S., Mohtasebi, S. S., Rafiee, H. (2010). Energy inputs-yield relationship and cost analysis of kiwifruit production in Iran. Renewable Energy, 35, 1071-1075.

Mousavi-Avval, S., H., Rafiee, S., Jafari, A., Mohammadi, A. (2011). Energy flow modeling and sensitivity analysis of inputs for canola production in Iran. Journal of Cleaner Production, 19(2011), 1464-1470.
Özcan, M. T. (1986). Mercimek hasat ve harman yöntemlerinin iş verimi, kalitesi, enerji tüketimi ve maliyet yönünden karşılaştırılması ve uygun bir hasat makinası geliştirilmesi üzerine araştırmalar. Türkiye Zirai Donatım Kurumu Yayınlarl, Yayın No: 46, Ankara.

Öztürk, H.H., (2011). Bitkisel Üretimde Enerji Yönetimi, Hasad Yayıncılık

Pimentel, D. (1980). Handbook of energy utilization in agriculture. CRC Press, Boca Raton.

Robinson, R. W., Decker-Walters, D. S. (1997). "What are Cucurbits". In Cucurbits, R. W. Robinson \& D. S. DeckerWalters, CAB International, New York. pp: 1-22.

Sağlam, C., Çetin, B. (2018). A research on determination of energy efficiency in pumpkin seed production. IV. International Vocational and Technical Sciences Congress, 2070-2076.

Saltuk, B. (2019a). Energy efficiency of greenhouse tomato production in Turkey: A case of Siirt province. Fresenius Environmental Bulletin, 28(8), 6352-6357.

Saltuk, B. (2019b). Determination of energy efficiency in after groundnut production (Osmaniye Case). Fresenius Environmental Bulletin, 28(4A), 3476-3482.

Singh, J.M. (2002). On farm energy use pattern in different cropping systems in Haryana, India. International Institute of Management University of Flensburg, Sustainable Energy System and Management. Master of Science. Germany.

Singh, H., Mishra, D., Nahar, N.M., Ranjan, M. (2003). Energy use pattern in production agriculture of a typical village in Arid Zone India (Part II). Energy Conversion and Management, 44, 1053-1067.

Sonmete, M. H. (2006). Fasulyenin hasat-harman mekanizasyonu ve geliştirme olanakları. Doktora Tezi, Selçuk Üniversitesi Fen Bilimleri Enstitüsü (Yayımlanmamış), Konya.

Sönmez, K., Alan, Ö., Kınac1, E., Kınacı, G., Kutlu, İ., Budak Başçiftçi, Z., Evrenosoğlu, Y. (2013). Bazı Şeker Mısır Çeşitlerinin (Zea mays saccharata Sturt) Bitki, Koçan ve Verim Özellikleri. Ziraat Fakültesi Dergisi, 8 (1), 28-40.

Tozan, M., Ergüneş, G., Özgün, E. (2001). Gökhöyük Tarım İşletmesinde Bitkisel Üretimde Tarımsal Mekanizasyon Özelliklerinin ve Enerji Bilançosunun Belirlenmesi. Tarımsal Mekanizasyon 20. Ulusal Kongresi 13-15 Eylül, Şanlıurfa.

TÜİK, 2021. Türkiye İstatistik Kurumu. http://www.tuik.gov.tr Erişim Tarihi: 13.04.2021.

Uhlin, H. (1998). Why energy productivity is increasing: an I-O analysis of Swedish agriculture. Agricultural Systems, 56(4), 443- 465.

Yadav, S. N., Chandra, R., Khura, T. K., Chaukan, N. S. (2013). Energy input-output analysis and mechanization status for cultivation of rice and maize crops in Sikkim. Agricultural Engineering International: CIGR Journal, 15(3), 108-116.

Yılmaz, H., Aydın, B. (2020). Comparative input-output energy analysis of citrus production in Turkey: Case of Adana province. Erwerbs-Obstbau, 62, 29-36. 